\title{
Pi-GST Excretion Rate
}

National Cancer Institute

\section{Source}

National Cancer Institute. Pi-GST Excretion Rate. NCI Thesaurus. Code C119279.

A determination of the amount of pi glutathione-s-transferase being excreted over a defined period of time. 